\title{
O fim das fraternidades raciais latino-americanas no imaginário afro-americano: a viagem de George Schuyler pela América Latina (1948)
}

\author{
Flavio Thales Ribeiro Francisco ${ }^{1^{*}}$ \\ ${ }^{1}$ Universidade Federal do ABC, São Bernardo/SP - Brasil
}

\section{RESUMO}

O objetivo deste artigo é o de analisar o relato de viagem do intelectual afro-americano George Schuyler pela América Latina em 1948. A sua intenção era a de retratar a presença e as experiências dos negros nas forças armadas dos países latino-americanos, comparando-as com a situação dos negros nas forças armadas estadunidenses. Naquele mesmo ano, o presidente Harry Truman havia assinado uma ordem executiva para iniciar o processo de desagregação das forças armadas, tentando assegurar o voto dos negros em uma eleição disputada com outros dois candidatos. O jornal Pittsburgh Courier, no qual atuava George Schuyler, interessado em promover o debate sobre a inclusão de negros nas forças armadas, financiou a sua viagem pela América Latina. Schuyler acreditava na ideia, compartilhada entre várias lideranças negras, de que as sociedades latino-americanas, apesar da pobreza material, eram muito mais inclusivas que a estadunidense, possibilitando a mobilidade social das populaçôes negras pelo continente, principalmente no Brasil. Entretanto, ao testemunhar a realidade dos negros latino-americanos, o intelectual fez um retrato distinto das representaçôes difundidas entre os afro-americanos, apontando para a coexistência entre miscigenação e preconceito racial, um fenômeno considerado contraditório para estudiosos das relaçôes raciais naquele momento.

Palavras-chave: racismo; imprensa negra; relatos de viagem; democracia racial.

DOI: http://dx.doi.org/10.1590/2237-101X02104506

Artigo recebido em 21 de dezembro de 2018 e aceito para publicaçáo em 10 de dezembro de 2019.

* Professor da Universidade Federal do ABC / Centro de Engenharia, Modelagem e Ciências Sociais Aplicadas/ Relaçôes Internacionais, São Bernardo/ SP - Brasil. E-mail: flaviusnet@hotmail.com. ORCID: https:// orcid.org/0000-0003-1617-9773. 


\title{
The end of Latin American racial fraternities in the African American imaginary: George Schuyler's trip through Latin America (1948)
}

\begin{abstract}
This article analyzes African American intellectual George Schuyler's 1948 Latin American travel narrative. His intent was to recount the experiences of Black people in the armies of Latin American countries in order to compare them to the experiences of Black people in the United States' armed forces. That same year, US President Harry Truman, in an effort to attract the vote of Black citizens in a tight election race, signed an executive order that began the process of desegregating the army. The Pittsburgh Courier, where Schuyler worked, sponsored his trip to Latin America because it was interested in promoting the debate about including Black people in the armed forces. Before he left, Schuyler believed in the idea, shared by many Black leaders at the time, that Latin American countries were more racially inclusive than the United States, which enabled Black people there to be more upwardly mobile. However, witnessing the experiences of Black people in Latin America changed his mind. His account pointed to the coexistence of miscegenation and racial prejudice, a phenomenon that scholars of race relations at that time considered a contradiction.
\end{abstract}

Keywords: racism; black press; travel narrative; racial democracy.

\section{El fin de las fraternidades raciales latinoamericanas en el imaginario afroamericano: el viaje de George Schuyler por la América Latina (1948)}

\section{RESUMEN}

El objetivo de este artículo es el de analizar el relato del viaje del intelectual George Schuyler por la América Latina en 1948. Su intención era retratar la presencia y la experiencia de los negros en las fuerzas armadas de los países latinoamericanos, comparándolas con la situación de los negros en las fuerzas armadas estadounidenses. En este mismo año, el presidente Harry Truman había firmado una orden ejecutiva para iniciar el proceso de desagregación de las fuerzas armadas, intentando asegurar el voto de los negros en una elección disputada con otros dos candidatos. El periódico Pittsburgh Courier en el cual actuaba George Schuyler, interesado en promover el debate sobre la inclusión de negros en las fuerzas armadas, financió su viaje por la América Latina. Schuyler, creía en la idea, compartida entre varios líderes negros, de que las sociedades latinoamericanas, a pesar de la pobreza material, eran mucho más inclusivas que la estadounidense, posibilitando la movilidad social de las poblaciones negras por el continente, principalmente en Brasil. Sin embargo, al evidenciar la realidad de los negros latinoamericanos, el intelectual hizo un retrato diferente de las representaciones difundidas entre los afroamericanos, apuntando para la coexistencia entre el mestizaje y el 
prejuicio racial, un fenómeno considerado contradictorio para los estudiosos de las relaciones raciales de ese momento.

Palabras clave: racismo; prensa negra; relatos de viaje; democracia racial.

Em 1966, o jornalista negro George Schuyler lançava a sua autobiografia, com o principal objetivo de se firmar como uma voz do conservadorismo negro nos Estados Unidos. Em Black and Conservative: the autobiography of George Schuyler, desenvolveu uma narrativa na qual destacou a formação de um intelectual conservador, influenciado não somente pela ascensão de uma oposição a Franklin Roosevelt no campo da direita, mas também pelos valores de sua família, orientados fortemente pela noção de respeitabilidade e individualidade (SCHUYLER, 1966). Schuyler, para afirmar o seu lugar no campo conservador, reelaborou a narrativa sobre sua trajetória, identificando os seus valores nos laços familiares. De maneira nostálgica, reproduziu os comentários preconceituosos de sua avó sobre os migrantes negros do Sul do país que começavam a se instalar na cidade de Syracuse, redefinindo os espaços da população afro-americana no estado de Nova Iorque nos primeiros anos do século XX. Naquele contexto, havia uma hierarquia simbólica entre as famílias negras que já habitavam as cidades do Norte e os migrantes que fugiam da crise econômica e da violência do Sul. Na visão dos grupos negros já estabelecidos, como era o caso dos Schuylers, os migrantes negros sulistas não entendiam as etiquetas de civilidade das cidades do Norte devido à falta de educação e deveriam ser disciplinados para compreenderem as dinâmicas do mercado de trabalho.

Outro aspecto importante destacado por George Schuyler em sua autobiografia foi a sua passagem pelo campo da esquerda: o seu trânsito por organizaçóes socialistas no começo de sua trajetória foi reinterpretado como um erro decorrente da sua falta de maturidade. Por outro lado, a sua própria experiência no socialismo foi explorada para demonstrar os limites da ideologia e seu "caráter anômalo" na tradição política estadunidense. O intelectual negro revelaria ao longo de sua carreira como jornalista o seu incômodo com algumas organizações políticas de base popular, ressaltando sempre a importância de entidades capazes de difundir uma cultura da individualidade entre os afro-americanos. Para Schuyler, o avanço dos negros no campo da economia através do empreendedorismo era muito mais interessante e efetivo do que o enfrentamento político para a conquista de uma cidadania negra de primeira classe nos Estados Unidos.

Nesse sentido, é possível compreender como uma voz importante da "América Negra" se enveredou para um outro extremo do espectro político enquanto o Movimento pelos Direitos Civis galvanizava as principais lideranças negras do país em uma agenda integracionista que ganhava cada vez mais espaço no cenário político. George Schuyler sempre reconheceu 
o problema da segregação racial e, principalmente, da noção de raça que estruturava as hierarquias sociais nos Estados Unidos. Entretanto, para Schuyler, Martin Luther King não passava de uma liderança demagoga e irresponsável que conduzia a população negra para um embate racial que apenas aprofundaria a violência racial no país. $\mathrm{O}$ intelectual fazia parte de uma linhagem de moderados e conservadores que enfatizavam a importância de uma abordagem gradualista, privilegiando o progresso da população negra a partir de iniciativas na esfera da economia que teria como consequência a inclusão dos negros em longo prazo, sem que houvesse o custo do enfrentamento (EISENSTADT, 2012).

Booker T. Washington foi uma das figuras mais importantes do conservadorismo negro nos Estados Unidos. Washington, que ascendeu como liderança na virada entre os séculos XIX e XX, enfatizava frequentemente a importância do empreendedorismo para avanço da população afro-americana, criticando as agendas do ativismo negro que reivindicavam a igualdade de direitos e acirravam as tensóes com os supremacistas brancos. Para a liderança negra que havia construído sua carreira política nos espaços segregados do Sul, a conquista de uma cidadania de primeira classe seria concluída a partir de um processo cauteloso e gradual de avanços econômicos. Outra figura importante foi Plummer Bernard Young, que nas décadas de 1930 e 1940 difundiu os princípios do acomodacionismo (termo associado à agenda de Booker T. Washington) entre os negros do Sul a partir de suas publicaçóes. Young, assim como Washington, fez parte de um conservadorismo popular comum entre os negros do Sul, que perdeu espaço com a ascensão do Movimento pelos Direitos Civis na década de 1960 .

A popularidade da agenda de Martin Luther King entre as comunidades negras do Sul, alcançada através de mobilizações populares que confrontavam as políticas segregacionistas, reduziu o espaço de circulação dos princípios conservadores, relegando as figuras negras conservadoras a uma subcultura do conservadorismo norte-americano. No período em que Schuyler passou a se identificar como conservador, o Partido Republicano, que por anos havia sido identificado com pautas progressistas como o abolicionismo, começou a incorporar uma agenda conservadora que definiria a sua atual identidade. Ou seja, Schuyler faz o deslocamento para o campo conservador em um momento que os princípios de Washington já não tinham tanta popularidade. Nesse processo, os conservadores negros passaram a cumprir mais o papel de interlocutores com o conservadorismo estadunidense do que lideranças capazes de influenciar as agendas políticas dos afro-americanos.

No entanto, George Schuyler, antes que aderisse efetivamente ao conservadorismo, contribuiu com figuras progressistas da militância afro-americana. De fato, a narrativa estruturada em sua autobiografia não deu conta da ampla rede da qual fez parte entre 1920 e 1940 . Algumas inconsistências se revelariam já nas informações sobre o seu nascimento, apontadas pelo historiador Oscar Williams (2007). A indicação era a de que o intelectual nascera em 1895, mas não há nenhum registro, e sua mãe, Eliza Schuyler, foi registrada no censo de 
1900 como uma mulher solteira e sem filhos. A hipótese do historiador é de que o jornalista tenha omitido a sua adoção. $\mathrm{Na}$ autobiografia, Schuyler enfatizou a linhagem distinta de sua família, que se estendia até a independência das colônias britânicas e a fundação da República estadunidense. Em seu relato, ele retrata a história de uma família de negros livres durante um longo período da escravidão. $\mathrm{O}$ seu avô havia lutado nas tropas americanas e, após a independência, conquistou a sua liberdade. O prestígio dos Schuylers, apesar de não experimentarem nenhuma experiência de ascensão social, residia em uma narrativa na qual a opressão da escravidão era um fenômeno distante que não afetara a linhagem familiar.

A história da família de George Schuyler demonstra o apego simbólico a uma reputação que não viabilizou o seu acesso a alguma ocupação de prestígio no mercado de trabalho. Assim como grande parte dos homens negros engajados na estratégia de ascensão social no funil da hierarquia racial estadunidense, Schuyler se alistou nas forças armadas. O exército, com todas as práticas corriqueiras e sistemáticas de discriminação, lhe possibilitou o exercício intelectual por meio do trabalho de jornalista em uma publicação que circulava entre os militares. Schuyler nunca recebeu a promoção na hierarquia militar que esperava depois de tanta dedicação, mas o aprendizado foi importante para a sua carreira como jornalista que se iniciaria no jornal socialista The Messenger. Após conhecer Rudolph Philips, eminente socialista negro, em 1922, George Schuyler começou a escrever em uma coluna na qual discutia questôes mais candentes do universo afro-americano, principalmente as que envolviam os atos violentos da organização terrorista Ku Klux Klan contra cidadãos negros.

O seu estilo sarcástico atraiu atenção de ativistas e intelectuais negros, sendo que grande parte deles se transformaria em alvo de sua língua afiada. No momento em que a imprensa negra ganhava fôlego nos Estados Unidos, com vários jornais ampliando a circulação em território nacional, Schuyler, que ganhara popularidade, passou a colaborar em outros periódicos (WATSON, 2013). Em 1925, o jornal Pittsburgh Courier, até entâo uma publicação de circulação local, resolvera colocar em prática a estratégia de competir nacionalmente com outros periódicos. George Schuyler, assim, foi identificado pelos investidores do Courier como um trunfo para a promoçáo do jornal nacionalmente. A parceria se iniciou com a publicação de alguns artigos e, posteriormente, foi reforçada por uma reportagem sobre as relaçôes raciais nos estados do Sul do país. Os relatos de Schuyler publicados no jornal tiveram um retorno positivo dos leitores, contribuindo para a sua expansão. No Pittsburgh Courier, George Schuyler se consolidaria como uma das vozes da "América Negra”, influindo de maneira decisiva no debate sobre a questâo racial no país.

No início da década de 1930, o jornalista publicou dois livros. Em Black no more (SCHUYLER, 1931a), tratou da obsessão dos estadunidenses com as categorias raciais, em um romance que conta a história de negros que se transformam em brancos através de uma máquina, desorganizando as dinâmicas sociais que sustentavam a supremacia branca no país. Já em Slaves of today (SCHUYLER, 1931b), George Schuyler publicou 
a investigação que fez na Libéria sobre os regimes de trabalho forçado no país. É nesse momento também que o intelectual passou a manifestar a sua insatisfação com organizaçôes socialistas e comunistas dos Estados Unidos. Em 1931, atacou o Partido Comunista durante o caso dos "garotos de Scottboro", incriminados injustamente por abusarem de duas garotas brancas. Schuyler acusou os comunistas, que competiam com organizaçóes políticas negras a defesa dos réus, de estarem interessados somente nos holofotes e não no bem-estar dos garotos. Para ele, os defensores oferecidos pelo Partido Comunista, que tinham a desaprovação de muitos cidadãos estadunidenses, poderiam comprometer ainda mais a situação dos réus.

Os comunistas nos Estados Unidos são mais uma ameaça do que uma promessa. A intenção deles é a de ganhar capital político com a questão racial, assim como Bleases e Heflins fazem no Sul. Eles não se importam com os negros que eles querem defender. O que eles procuram fazer é a promoção de atividades revolucionárias para a derrubada do governo. ${ }^{2}$

Antes que sua tendência conservadora se acentuasse na década de 1950, com uma caça aos comunistas nos Estados Unidos - promovida pelo senador Joseph McCarty em um contexto de Guerra Fria - Schuyler cumpriu um papel importante na agenda integracionista nas forças armadas. A campanha da "Dupla Vitória", encampada pelo jornal Pittsburgh Courier, revelou a capacidade de articulação do movimento negro na década de 1940, num momento no qual o eleitorado negro, mesmo sem contar com a participação dos eleitores vítimas da segregação do Sul, se transformava em um grupo de pressão nas eleiçóes presidenciais. O objetivo da campanha era o de garantir a participação dos negros como soldados na Segunda Guerra Mundial, principalmente nas frentes de combate. O discurso da militância sobre a importância de uma política de integração para efetivação da democracia estadunidense foi explorado pelo Pittsburgh Courier, que acabou se consolidando como o principal periódico da imprensa negra. Schuyler, que em um primeiro momento manifestou uma certa resistência para apoiar o governo de Roosevelt, por conta da intervenção demasiada na economia, posteriormente se engajou na campanha da Dupla Vitória.

O jornalista e intelectual negro cumpriu um papel primordial na popularização do Pittsburgh Courier, entretanto o seu conservadorismo acabaria comprometendo a sua relação com os editores do jornal, mesmo que a publicação apresentasse uma política editorial considerada por muitos como moderada. A sua implicância com Martin Luther King, principal

\footnotetext{
${ }^{2}$ SCHUYLER, George. View and review. Pittsburgh Courier, 18 jul. 1931. Tradução do autor. No original: "The Communists in the United States are more of a menace than a promise to Negroes. Their policy is to make pollical capital out of the race problem, just like Bleases and Heflins do down South. They care nothing for the individual unfortunate Negroes they appear eager to defend. What they are seeking to do is to stir up revolutionary activity and sentiment toward the day when the government can be overthrown".
} 
liderança do Movimento pelos Direitos Civis, enfureceu muitos leitores num momento em que o ativismo negro ganhava terreno e atraía a atenção de seguimentos liberais.

Ser articulado não significa muita coisa, alguns dos maiores inimigos dos negros são articulados. Você está errado se pensa que o Reverendo King e sua laia de idiotas têm feito mais para os negros do que NAACP e a Urban League, organizações com políticas baseadas na inteligência e na experiência, e muito bem executadas. Novamente, o constrangimento do Sul só vale a pena se não causar represálias. E quais são as armas dos negros [nos conflitos com brancos sulistas], senão o protesto? ${ }^{3}$

Por um período, George Schuyler conseguiu sobreviver politicamente com a publicação de seus textos em periódicos conservadores, interessadas na perspectiva de um negro conservador. Contudo, o jornalista foi perdendo espaço e jamais conseguiu recuperar o prestígio que havia alcançado no Pittsburgh Courier.

\section{A campanha da Dupla Vitória e a ascensão do Pittsburgh Courier}

Os relatos de George Schuyler sobre a sua jornada pelo Sul do país deram o primeiro impulso ao Pittsburgh Courier na disputa pelos leitores negros em escala nacional com outros periódicos da imprensa afro-americana. Ao longo da década de 1930, a Grande Depressão, que teve um impacto maior sobre a populaçáo negra, atingiu profundamente as vendas dos periódicos. O Chicago Defender, que alcançou o patamar de 250 mil exemplares por edição no final da década de 1920, perdeu uma ampla base de leitores e o título de maior semanário negro em circulação no país. O incremento da infraestrutura do Pittsburgh Courier em 1929 ajudou no enfrentamento da crise, propiciando a liderança na década de 1940 (BUNI, 1974; WATSON, 2012).

Nesse sentido, a campanha pela Dupla Vitória em 1942 foi um divisor de águas para o periódico, que assumiria o papel de liderança em uma articulação de jornalistas e ativistas negros contra segregação no exército estadunidense durante a Segunda Guerra Mundial. A campanha teve grande repercussão entre o público afro-americano, impulsionando as vendas do Pittsburgh Courier e transformando-o no periódico de maior circulação da imprensa

\footnotetext{
${ }^{3}$ SCHUYLER, George [correspondência]. Destinatário: William G. Nunn, 1962. Schuyler Papers - Syracuse University. Tradução do autor. No original: "Being articulate also means nothing in itself. Some of the worst enemies of the Negro have been articulate. And you are quite wrong if you think that Rev. King and his crackpot ilk are accomplishing more for Negroes than the NAACP and the Urban League, which have a more definitive policy based on experience and intelligence, and are carrying it out. Again, embarassament of the South...is only worthwhile to the extent that it does not stir reprisals - and what have Negroes go to fight with, except mouth?"
} 
negra nos Estados Unidos (WASHBURN, 1981). Apesar da posição moderada de alguns colunistas do jornal, que enfatizavam a importância da individualidade e do empreendedorismo para o progresso econômico dos negros, o jornal foi bem-sucedido, nas décadas de 1930 e 40, na sua aliança com organizaçóes políticas, como a NAACP, na luta pela igualdade de direitos.

Nesse período, os negros nos Estados Unidos se transformavam em um eleitorado expressivo nas eleiçóes presidenciais, apesar de o segregacionismo nos estados sulistas afastar a grande maioria da população negra do processo eleitoral. Durante a Grande Depressão, os negros, tradicionais eleitores do Partido Republicano, abandonaram o partido de Lincoln para apostar no New Deal de Franklin D. Roosevelt. Ainda que a discriminação se reproduzisse nos programas sociais do presidente democrata, havia a percepçáo entre o eleitorado negro que, pela primeira vez, desde o período da Guerra Civil, a administraçáo federal se preocupava com a situação dos menos abastados e os negros (WEISS, 1983). ${ }^{4}$ De fato, ainda que proporcionalmente os brancos desfrutassem mais as políticas públicas, muitos negros acessaram os programas de auxílios e promoção de empregos do New Deal, freando os efeitos acentuados da crise econômica sobre a população negra. Em sua primeira reeleição, Roosevelt obteve a maioria dos votos negros e deu início à longa relaçáo entre o grupo e o Partido Democrata.

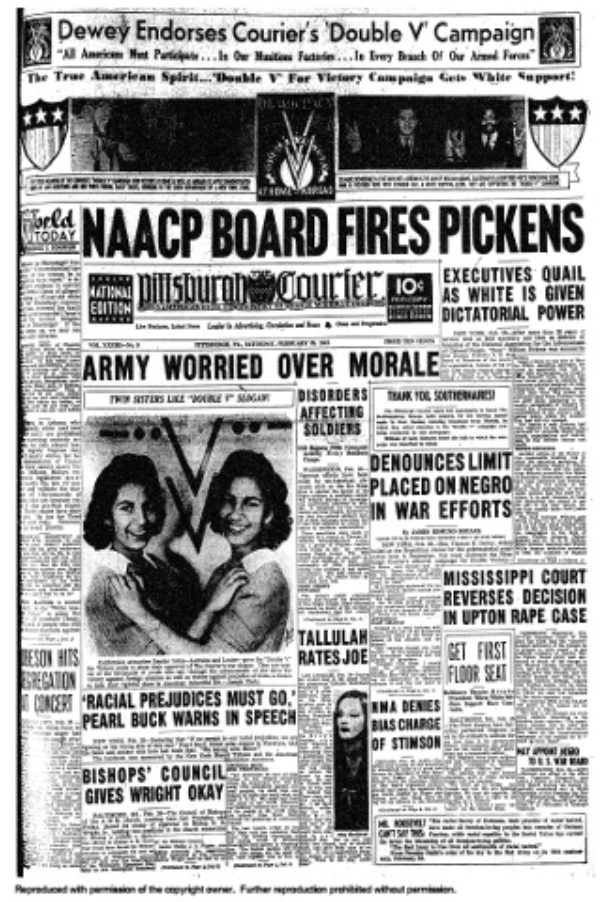

Figura 1: Primeira página do Pittsburgh Courier com a Campanha do "Duplo V”, em 1942.

\footnotetext{
${ }^{4}$ Ver também Katznelson (2006) e Sitikoff (2009).
} 
Desde então, algumas demandas do ativismo negro foram recebidas pelos presidentes com uma outra atenção. Anteriormente as agendas eram ignoradas sistematicamente por republicanos e democratas. Nesse contexto, sob liderança de Philip Randolph, o movimento negro ameaçou a organização de uma marcha sobre Washington para reivindicar uma lei antilinchamento e o fim da segregação nas forças armadas (O'REILLY, 1995). Como resposta à ameaça, o presidente Roosevelt aproveitou a retomada do crescimento econômico durante a guerra para elaborar um plano de inserção de trabalhadores negros na indústria bélica, que teve efeito limitado em seu início.

Em 1942, no mês de janeiro, a questão da integração racial nas forças armadas foi encampada pelo Pittsburgh Courier. O jornal colaborou para popularizar o debate entre o público afro-americano. A expressáo "dupla vitória" surgiu da retórica do governo de que a vitória dos Estados Unidos e de seus aliados significaria o triunfo da democracia. Nesse sentido, a participaçáo dos combatentes negros na guerra poderia contribuir para uma segunda vitória: o início da integração racial nas instituições estadunidenses, principalmente no Sul do país. O leitor James Thompson, entusiasmado com a conjuntura, enviou uma carta para o periódico, sugerindo o apoio da população negra às forças armadas. O Pittsburgh Courier, estimulado pelo patriotismo do leitor e o potencial de um movimento de luta pela integração, deu início à campanha da Dupla Vitória (WASHBURN, 1981, p. 3). Vários periódicos exploraram a euforia em torno do conflito, mas foi o Pittsburgh Courier que teve o maior retorno dos leitores. O periódico incentivou a organizaçáo de "Clubes da Dupla Vitória" entre as comunidades negras, que constituíram grupos que organizavam eventos com o tema da campanha, promovendo desfiles, debates, concursos de beleza e a compra de títulos do governo para o financiamento da guerra. O sucesso da campanha transcendeu a esfera pública afro-americana e repercutiu entre políticos e a grande imprensa dos Estados Unidos. Sobre o movimento, George Schuyler afirmou:

Eu acho que enquanto mantivermos defesa e vitória na linha de frente, não perderemos a nossa perspectiva de democracia em casa.

$\mathrm{O}$ símbolo $\mathrm{V}$ de vitória tem sido exibido proeminentemente em todos os países considerados democráticos que estão lutando pelo triunfo da democracia sobre a violência, tirania e escravidão. Se o V significa tudo isso para aqueles engajados no conflito, então deixe os afro-americanos adotarem o Duplo $\mathrm{V}$ para uma vitória dupla. O primeiro $\mathrm{V}$ para a vitória sobre os inimigos estrangeiros, o segundo para a vitória sobre os inimigos internos. Aqueles que perpetuam o preconceito aqui estão destruindo nossa democracia, assim como as forças do Eixo. ${ }^{5}$

\footnotetext{
${ }^{5}$ SCHUYLER, George. Views and reviews. Pittsburgh Courier, 31 jan. 1942, p. 3. Tradução do autor. No original: "The $\mathrm{V}$ for victory sign is being displayed prominently in all so called democratic countries which are fighting for victory over aggression, slavery and tyranny. If this $\mathrm{V}$ sign means that to those now engaged in this great conflict, then let we colored Americans adopt the double VV four a double victory. The first $\mathrm{V}$ for victory over our enemies from without, the second $V$ for victory over our enemies from within. For surely
} 
Nesse contexto de guerra, George Schuyler, em um primeiro momento, fez críticas ao governo norte-americano. $\mathrm{O}$ seu argumento não era necessariamente contra uma luta pela democracia alhures, mas contra o tamanho e o papel do estado na vida dos indivíduos. $\mathrm{O}$ intelectual negro se alinhara aos opositores do New Deal que questionavam a "militância" do governo de Franklin Roosevelt na economia do país (POGGI, 2008). Em um Estado que reproduzia as desigualdades raciais da sociedade em suas políticas públicas, segundo Schuyler, não fazia sentido a participação dos negros em uma guerra. Entretanto, assim como outros jornalistas e líderes negros, quando percebeu a euforia dos afro-americanos com a participação dos combatentes negros e a possiblidade de promoção de políticas de integração racial, acabou aderindo à campanha da Dupla Vitória. Além de discutir a questão do negro na guerra, o jornalista colaborou com entrevistas de celebridades do universo afro-americano que apoiaram o movimento.

A campanha durou apenas um ano, no início de 1943, o Pittsburgh Courier continuou a promover a cobertura da atuação dos combatentes na Segunda Guerra Mundial, mas sem utilizar nenhuma referência à campanha. Uma das razóes foi o fato de que as políticas de inserção de trabalhadores negros na indústria começaram a surtir efeito, diminuindo a pressão da população negra sobre o governo federal. Por outro lado, o FBI passou a intimidar os jornalistas da imprensa negra, pois os policiais federais entendiam que as notícias sobre violência racial no país poderiam comprometer a imagem dos Estados Unidos enquanto referência de democracia no exterior. George Schuyler, especificamente, foi vigiado por seus comentários em sua coluna, na qual criticava enfaticamente campos de concentraçáo de japoneses no país (WILLIAMS, 2007, p. 107).

Com relação às políticas de integração racial nas forças armadas, só foram implementadas a partir de 1948, depois do presidente Harry Truman assinar uma ordem executiva. Naquele momento, ele encarava uma disputa acirrada nas eleiçóes e náo poderia desperdiçar os votos dos afro-americanos (RAWNS JR., 2013). Em meio a esse processo, George Schuyler retomou a ideia de fazer uma jornada pela América Latina para analisar a composiçáo racial das forças armadas nos países abaixo do Rio Grande. No mesmo ano, o jornalista visitou Cuba, Panamá, Colômbia, Venezuela, Peru, Brasil, Argentina, Uruguai e Chile.

\section{A viagem de George Schuyler pela América Latina}

Assim, o jornalista realizou um périplo pela América Latina similar ao do jornalista Robert Abbott em 1923. O editor do Chicago Defender publicou em seu jornal os relatos de viagem aos países latino-americanos, cujo objetivo era o de compreender as dinâmicas

those who perpetuate these ugly prejudices here are seeking to destroy our democratic form of government just as surely as the Axis forces". 
de relaçôes raciais que fossem distintas do padrão estadunidense. Abbott compartilhava da ideia, que se reforçava naquele momento, de que não havia problema de raça ou de cor entre os latino-americanos (HELLWIG, 1992). Nas páginas do Chicago Defender, ele difundiu sistematicamente a existência de paraísos raciais no continente, revelando a sua admiração pelo Brasil ao transformá-lo em referência de ordem social livre de práticas racistas para confrontar os discursos de supremacia branca nos Estados Unidos (FRANCISCO, 2016).

De certa forma, ao propor uma viagem para analisar os padrões de relações na América Latina, Schuyler também revelou a sua crença no excepcionalismo racial do continente. Para encaminhar o projeto de integração racial nas forças armadas norte-americanas, que poderia desencadear políticas de promoção de igualdades no país em outras áreas, era necessário compreender a inserção dos negros nas forças armadas das naçôes latino-americanas. Uma vez mais, a América Latina era tratada como exemplo positivo de integração para os afro-americanos que lutavam por uma agenda inclusiva. A busca por referências nas forças armadas latino-americanas foi uma das últimas iniciativas de George Schuyler antes de se transformar definitivamente em uma voz conservadora que se opunha às principais lideranças do movimento negro nos Estados Unidos.

Os relatos foram publicados em forma de artigos no Pittsburgh Courier. Contudo, apesar de mais extensos, não tiveram uma seção específica no periódico. Foram sete relatos sobre a viagem de George Schuyler, além de várias colunas e notícias paralelas que acabaram rendendo cerca de 20 artigos sobre o assunto. Além de informar os leitores sobre as condiçôes dos negros nas forças armadas, Schuyler explorou outros aspectos como mercado de trabalho, ascensão social, empreendimentos, atuação na política e ativismo. Ao divulgar a jornada de Schuyler, o Pittsburgh Courier ignorou a viagem anterior de Robert Abbott e anunciou o ineditismo da viagem pelas "irmãs da América do Sul".

George Schuyler teve como primeira parada a ilha cubana, e o artigo publicado no jornal foi destacado com o título "a integração racial funciona no exército cubano". ${ }^{6} \mathrm{O}$ jornalista chegou a essa conclusão após testemunhar o cotidiano de militares cubanos, em que brancos e negros compartilhavam os mesmos espaços e desempenhavam as mesmas atividades. O fato de brancos terem de obedecer às ordens de superiores negros na hierarquia militar chamou a atenção de Schuyler, que acompanhou de perto a rotina do general negro Gregory Guarejeta. Entretanto a ausência de segregação racial nas forças armadas não foi suficiente para promover negros e mulatos para os altos escalóes. $\mathrm{O}$ jornalista observou que, além de Guarejeta, não havia nenhum outro oficial negro na mesma posição hierárquica ou superior no exército. Na Marinha também havia apenas um oficial negro e, na aeronáutica, náo existia nenhum. Schuyler demonstrou como as posiçôes de prestígio na hierarquia militar eram ocupadas por uma espécie de "aristocracia" que tinha acesso facilitado pelas academias militares.

\footnotetext{
${ }^{6}$ SCHUYLER, George. Racial integration works in Cuba's army. Pittsburgh Courier, 17 jul. 1948, p. 1.
} 
Assim como era comum para os estadunidenses que viajavam pela América Latina, o jornalista teve de encarar o desafio de compreender no dia a dia as dinâmicas das relaçóes sociais dos cubanos. Schuyler utilizou três categorias (negro, mulato e branco) para demonstrar como uma sociedade com um processo intenso de miscigenação e sem segregação racial poderia criar desigualdades a partir da cor da pele. ${ }^{7}$ A questão de classe parecia ser mais influente entre os cubanos do que a questáo racial, entretanto ele observara que a elite do país era formada predominantemente por brancos: "os negros tinham pouco, os mulatos um pouco mais e os brancos levavam uma boa vida". "Nesse sentido, o mercado de trabalho, segundo o jornalista, apresentava práticas discriminatórias que inviabilizavam a presença de negros em algumas áreas. Não havia negros trabalhando como vendedores em lojas, na companhia telefônica, no telégrafo ou em escritórios. George Schuyler identificou alguns engenheiros negros, mas reforçou a informação de que não havia médicos e enfermeiros negros nos hospitais privados e um número pequeno de políticos. $\mathrm{O}$ jornalista conversou com o grande intelectual Fernando Ortiz, que afirmou que ainda havia muito preconceito de cor, mas que a sociedade cubana estava avançando.

Uma evidência de que a discriminação de cor não está desaparecendo é o fato de não haver um médico ou enfermeiro negro no quadro de funcionários de nenhum hospital privado de Havana, depois fiquei sabendo que havia apenas um médico negro entre os hospitais públicos. Ainda que na cidade existam 300 médicos negros e até um número maior de dentistas, eles aparecem apenas na folha de pagamento por motivos políticos. Cerca de 35 por cento dos 10 mil estudantes da universidade pública de Havana são negros, porém há apenas um professor negro na instituição, a Dra. Ana Echegoyen, da área de educação.

No relato sobre Cuba, apesar de não identificar o preconceito nas forças armadas, Schuyler desenhou um quadro nada favorável para a população negra. Ele também descreveu a perseguição policial sobre a população de cor e a condição insalubre de famílias negras que viviam em cortiços. Entretanto havia a expectativa de que a sociedade cubana propiciasse mais oportunidades aos negros no futuro.

Nos relatos seguintes, sobre a Venezuela e o Panamá, George Schuyler não encontrou melhores perspectivas para os negros. Nos dois países, identificou relações raciais de padróes

\footnotetext{
${ }^{7}$ Idem.

${ }^{8}$ Idem.

${ }^{9}$ Idem. Traduçáo do autor. No original: "Further evidence of color discrimination which is not too swiftly giving way is the fact that there is not a single Negro physician or nurse on the staff of any private hospital in Havana and it was possible to learn of only one Negro doctor on the staff of a public hospital. Although the town swarms with some 300 Negro physicians and even more Negros dentists, many of whom are, however, on the public payroll doubtless for political reasons. Although 35 per cent of 10.000 students at publicly supported University of Havana are colored, there is only one Negro instructor on its staff, a woman, Dra Ana Echegoyen, who teaches education".
} 
distintos que eram consequência de duas diferentes histórias. No caso dos panamenhos, o jornalista destacou a influência dos norte-americanos sobre o país, que acabou estruturando uma hierarquia racial similar ao do Sul dos Estados Unidos. Na zona do Canal do Panamá, onde os norte-americanos dominavam politicamente, as ocupaçóes de prestígio eram ocupadas por brancos e os trabalhos braçais eram desempenhados exclusivamente pelas populaçốes negras. Naquela regiáo havia uma divisão entre a "fila de ouro" e a "fila de prata", a primeira representando os brancos norte-americanos privilegiados e a segunda os trabalhadores negros. Essa separação determinava a segregação também na moradia, nos espaços recreativos e nas escolas. Schuyler ressaltou, o tempo todo, a discrepância entre um país com leis inclusivas e o poder político dos ianques que as subvertia.

Naturalmente os clubes, os playgrounds, o boliche e os restaurantes são "ouro" e "prata", isto é, racialmente segregados. Os trabalhadores de prata não têm quadras de esporte para as suas crianças e os playgrounds não são supervisionados. É comum que um gerente de um "clube de ouro" ganhe 375 dólares por mês, enquanto nos "clubes de prata" ganhe apenas 185 dólares. Não há dúvida de que a educação é segregada também, com as mesmas disparidades que encontramos nos Estados Unidos. Em uma escola de Ensino Fundamental de "ouro" os professores recebem entre 250 e 375 dólares por mês. Os professores das escolas de "prata" ganham no máximo 120 dólares com um salário inicial de 90 dólares. Em escolas de Ensino Médio de "prata" os professores conseguem um salário de 130 dólares e 160 dólares. Tanto os jovens de "ouro" como os de "prata" têm acesso ao ensino médio, mas apenas os primeiros têm acesso à universidade.

Para coroar a situação macabra, há a questão dos cemitérios. Como se poderia esperar, há uma seção segregada em que os "cadáveres prateados" são enterrados entre meia-noite e 13 horas e os "cadáveres dourados" são enterrados no período da tarde. Estes não são enterrados por funcionários de "prata". ${ }^{10}$

No caso da Venezuela, não havia qualquer tipo de interferência exterior nas relaçôes sociais do país. Foi lá que o jornalista identificou um processo mais complexo de miscigena-

\footnotetext{
${ }^{10}$ SCHUYLER, George. America's canal zone policy is a disgrace. Pittsburgh Courier, 31 jul. 1948, p. 1. Traduçâo do autor. No original: "Naturally the club houses, playgrounds, bowling alleys and restaurants are "gold" and "silver", i. e., segregated racially. The "silver" workers lack gymnasiums, and the playgrounds for their children are not supervised. It is characteristic that a "gold" club house manager gets $\$ 375$ monthly while a "silver" manager gets $\$ 185$. Of course education is Jim Crow too, with usual disparities found in such systems in the States. Elementary school teachers average from $\$ 250$ to $\$ 375$ monthly from an entrance salary of $\$ 90$. "Silver" junior high school teachers can get as high as $\$ 130$, and senior high achool teachers in the Jim Crow system may attain the dizzy financial height of \$156. Both "gold" and "silver" children are provided with senior high school instruction, but the White youths in addition get junior college training. Natch! As a crowning macabre touch. We have the cemetery situation. As might be expected, there is a Jim Crow section in which "silver" cadavers may be interred between noon and 1:30 p.m. "Gold" employees who have passed to their reward may be buried in the early morning and the late afternoon. They are not buried by "silver" gravediggers who are reserved for colored only".
} 
ção que impedia o seu olhar racializado pela cultura estadunidense de identificar as origens raciais dos cidadãos venezuelanos. No país, durante os seus deslocamentos na cidade de Caracas, identificou poucos negros de pele escura. Entretanto fez questão de ressaltar a atuação dos líderes militares negros que tiveram um papel fundamental na independência do país, definindo um imaginário nacional com a grande presença de negros. Apesar de tudo, Schuyler descreveu uma tendência de embranquecimento entre os mulatos que era comum entre vários países da América do Sul. Tal fenômeno teria reforçado as políticas de imigração de europeus para o país, diminuindo a influência dos negros na sociedade. O jornalista, contudo, reforçou que esse processo não era uma influência dos Estados Unidos, mas de um preconceito já presente entre os venezuelanos:

A Venezuela, assim como o Brasil, a Guatemala, a Costa Rica e outros vários países têm demonstrado um desprezo por negros. Todos eles promovem a instalação de imigrantes para povoar seus vastos territórios (a Venezuela tem um território do tamanho do Texas e de Oklahoma juntos, mas apenas uma populaçáo de 1.299.638) e desenvolve os recursos naturais ainda não explorados.

Todos esses países, incluindo a Venezuela, estáo atraindo refugiados europeus e camponeses italianos, que são transportados por longas distâncias, mas eles se negam a buscar trabalhadores do Haiti e de outras ilhas caribenhas que fizeram um bom trabalho no Canal do Panamá. [...] [...] É fácil dizer que essas atitudes são promovidas por norte-americanos que são influentes por causa do petróleo, mas muitos dos brancos de origem hispânica que sempre se consideraram superiores a indígenas, mestiços e negros, resistem para se manterem no topo através de nepotismo e do monopólio. ${ }^{11}$

No relato sobre o Peru, George Schuyler anunciou o desaparecimento da pequena população negra no país. A sua afirmação se baseou em dados que indicavam o declínio de 80 mil no período colonial para cerca de 30 mil naquele momento. Nos países nos quais a presença de negros era considerada pequena, o jornalista lançou mão de uma narrativa histórica para evidenciar a importância dessa população na formação social, política e econômica. Schuyler

${ }^{11}$ SCHUYLER, George. Segregation does not exist in Venezuelan Armed Forces. Pittsburgh Courier, 24 jul. 1948, p. 1. Tradução do autor. No original: "Venezuela, like Brazil, Guatemala, Costa Rica and several other countries has acquired a sudden distaste for black. All of them crave immigrants to fill up their vast spaces (Venezuela is larger than Texas and Oklahoma combined, but has a population of only 1.299.638) and develop their vast natural resources now almost completely untapped. All of these countries, including Venezuela, are eagerly taking in European refugees and Italian peasants who are transported great distance at considerable expense, but they refuse to tap the great reservoirs of labor in Haiti and the British West Indies which was good enough to build and maintain the Panama Canal [...] It is easy to say that this attitude has been fostered by the Americans who are influential here because of the oil, but many of these creole Whites have always regarded themselves as superiors to the Indians, the mestizos and the blacks, and striven to remain on top by nepotism and monopoly". 
destacou a presença de africanos entre os europeus que participaram da conquista da América e nas guerras civis que marcaram a história do país. $\mathrm{O}$ argumento era o de que, apesar da pequena quantidade de negros, eles tiveram uma contribuiçâo fundamental para a constituição da nação. A participação constante nos confrontos armados, contudo, não garantiu uma presença razoável de negros nas forças armadas. Assim como no caso da Venezuela, eram poucos os militares que poderiam ser identificados como tal. No entanto, reforçou Schuyler, não havia qualquer tipo de prática segregacionista na lei, o acesso era garantido a todos os peruanos independentemente da cor da pele. Entre os oficiais das forças armadas, apresentavam-se os mesmos problemas que nos demais países: a dificuldade para ascender na hierarquia militar. Schuyler foi informado que o grande problema era a falta de educação dos negros que inviabilizava a indicação para os cargos de comando:

De qualquer forma, negros e mulatos oficiais são uma raridade. A maioria dos oficiais são brancos, mestiços (mistura de brancos e indígenas) e indígenas. Foi me dito que há alguns negros no exército, mas me parece que são uma "meia-dúzia". Eles admitem que não há negros na marinha e na força aérea, ninguém se lembra de que em algum momento na história existiu algum. Não me parece que o Peru siga um padrão latino-americano.

Enquanto quase todos esses países contratam os serviços militares de norte-americanos, náo se pode dizer que estes têm alguma responsabilidade pelo número escasso de negros e mulatos porque o preconceito de cor existia antes da formação dos Estados Unidos.

Foi alegado que a escassez de oficiais deste grupo étnico seja devido à falta de qualificação educacional de mulatos e negros. Esse argumento talvez faça sentido. ${ }^{12}$

A dificuldade para negros e mulatos alcançarem os mais altos postos da hierarquia militar foi um fenômeno comum em todos os países visitados. As justificativas variavam entre o "atraso" da populaçáo negra e a manifestação do "preconceito de cor" na sociedade e nas forças armadas. No caso da Colômbia, as barreiras nas hierarquias militares estavam relacionadas às diferenças regionais. Se no Peru, George Schuyler identificou poucos negros em Lima, o mesmo não aconteceria em algumas regiôes do território colombiano. $\mathrm{O}$ jornalista deu destaque para a província de Chocó, na região do Pacífico, onde os negros

\footnotetext{
${ }^{12}$ SCHUYLER, George. Negroes gradually vanishing in Peru. Pittsburgh Courier, 7 ago. 1948, p. 1. Tradução do autor. No original: "However that may be, Negro and mulatto officers are a rarity. The majority of the officers are white, mestizos (mixed white and Indian) and Indian. It was said that there was almost none on the Navy and Air Corps, and upon close questioning no one could recall having seen any, although maintaining that they did exist. This is unlikely if Peru follows the Latin-American pattern. While almost all of these countries hire U. S. military and naval missions, it is probably untrue that these are responsible for the scarcity of Negro mulatto officers because color prejudice existed here long before the United States came into existence. It was pointed out that the scarcity of officers of this ethnic group might be due to the exacting educational qualifications which very few negroes or mulattoes are able to meet. There may be something to this argument".
} 
predominavam. Em Bogotá, a situação era similar à de outros países, com a ausência de leis segregacionistas, possibilitando a entrada de negros, mas com uma presença ínfima entre os oficiais. A situação não era desalentadora em Chocó, havia alguns oficiais e representantes entre a classe política da região. Entretanto o problema era o fato de que os homens negros e mulatos, assim como homens em geral, fugiam do exército. Diferentemente dos Estados Unidos, a carreira militar não era considerada um caminho para a ascensão social para os segmentos mais populares.

A partir da composição predominantemente branca dos oficiais das forças armadas, é possível perceber o branqueamento na Colômbia, assim como no resto da América Latina. Isso é consequência da herança colonial espanhola e ibérica, quando brancos ibéricos se posicionavam no topo, os brancos criolos em um estamento inferior, mestiços e mulatos na intermediária e negros e índios na base.

Esse processo é exemplificado pelos atuais esforços para atrair imigrantes brancos da Europa, enquanto se recusam os trabalhadores das aéreas próximas que são negros. A teoria é a de que os Europeus são ideais para se misturar com a população, e podem se adaptar melhor às temperaturas da altitude.

Algumas pessoas têm culpado a persistência desse problema aos norte-americanos e suas influências econômicas, mas a branquitude se expressa desde um período anterior à chegada dos ianques. ${ }^{13}$

O Uruguai, retratado como representativo da área do Rio Prata, apresentou um cenário diferente para George Schuyler. Existia ali uma sociedade predominantemente branca, com a presença pequena de negros ocupados em cargos de pouco prestígio. O jornalista percorreu áreas comerciais de Montevidéu em busca de negros empreendedores, mas foi muito malsucedido. Schuyler enfatizou o fato de que os negros da região do Prata manifestavam uma "consciência racial" devido a organização de clubes negros, entretanto não deu nenhum detalhe sobre essas entidades. Em sua narrativa, retornou ao período de independência das naçóes latino-americanas, destacando a participação dos negros no exército formado no Vice-Reino do Prata. Se no presente os negros não faziam parte das forças armadas, o passado foi marcado pela atuação nas linhas de frente que lutaram pela emancipação do império espanhol

${ }^{13}$ SCHUYLER, George. Colombia's army gives...to US brass hats. Pittsburgh Courier. 14 ago. 1948, p. 1. Tradução do autor. No original: "As shown by the predominantly white composition of the officer corps of the armed forces, there persists a white complex in Colombia elsewhere in Latin America which is part of the Spanish colonial heritage when the Iberian whites were on top, the Creole whites bellow them, the mestizos and mulattoes a considerable rung lower, and the Negroes and Indians on the bottom. This is further indicated by the current efforts to get white immigrants from Europe while refusing those from nearby Caribbean areas who are Negroes. The theory is that the Europeans are a better adjust themselves to the rigors of the high altitudes. Some have tried to blame the persistence of this complex on white Americans here and their undoubted economic influence, but lilly-whiteism long antedated the arrival of the Yankees". 
nos regimentos segregados dos tempos coloniais. Schuyler, no entanto, demonstrou como a participação na guerra foi importante para a ascensão de negros na hierarquia militar uruguaia durante o século XIX. Apesar de apontar o processo de embranquecimento das sociedades latino-americanas, não chegou a mencionar o fenômeno no Uruguai e na Argentina, onde a imigração de europeus se processou de maneira acentuada (ANDREWS, 2007).

Negros e mulatos nas repúblicas do sul da América do Sul são poucos e não influentes economicamente, socialmente, politicamente ou intelectualmente. Eles não são rejeitados ou discriminados em espaços governamentais e públicos, os serviços estão todos disponíveis para eles, incluindo instituiçôes de ensino superior. Entretanto eles estão ocupados nas atividades marginais, não há negócios gerenciados por negros e raramente desempenham profissóes liberais. Os brancos falam de maneira respeitável com eles, mas sempre enfatizam o fato óbvio de que todos os negros são pobres..$^{14}$

O exercício de comparação de George Schuyler, presente em todos os relatos, aparece de maneira mais clara em sua análise sobre a sociedade brasileira. O peso da escravidão e a dimensão do território brasileiro foram destacados pelo jornalista, traçando, assim, uma história comum para o Brasil e os Estados Unidos. A importância dada por Schuyler pode ser identificada na quantidade maior de artigos dedicados ao país - três artigos específicos sobre os brasileiros. No primeiro deles, Schuyler tratou especificamente da experiência dos negros nas forças armadas brasileiras em sua passagem pelas cidades de Salvador e do Rio de Janeiro. No relato, entretanto, se reproduzem as mesmas narrativas sobre as experiências negras em outros países, com a avaliação de que não havia segregação racial e que a ascensão de negros na hierarquia militar não era um fenômeno comum. $\mathrm{O}$ jornalista, no título do relato, anunciou que as forças armadas brasileiras "envergonhavam os militares estadunidenses" por conta da inclusão dos negros. Schuyler se baseou, sobretudo, em suas observações das atividades dos militares, a maioria delas em regime de colaboração entre brancos, negros e mulatos, sem que houvesse qualquer tipo de tensão racial. Entretanto, ao tratar do caso de oficiais negros, percebeu uma controvérsia entre "comentários oficiais" que atestavam a presença de negros e mulatos no topo da hierarquia e "extraoficiais" que denunciavam "o preconceito de cor":

${ }_{14}$ SCHUYLER, George. Negroes negligible factor in Uruguay. Pittsburgh Courier. 28 ago. 1948, p. 1. Tradução do autor. No original: "Negroes and mulattoes in the southern republics of South America are few and far between, and everywhere they are a very negligible factor economically, socially, politically and intellectually. They are not disliked, not discriminated against in public places, and all government facilities and services are open to them, including institutions of higher education. But they work in marginal jobs, have no business and are rarely encountered in the profession of arts. White people speak tolerantly of them but always stress that these Negroes are very poor, which is simply emphasizing the obvious". 
Esse oficial declarou que 10 por cento das forças armadas brasileiras eram de negros, 60 por cento de mulatos e o restante de brancos. Ele ainda enfatizou que há três negros generais e 20 negros coronéis. Como um quarto da população é negra, ele atribuiu a pequena quantidade de negros oficiais à dificuldade de passar nos exames das academias do Exército, da Marinha e da Força Aérea. Esta é claramente uma visão oficial.

[...] Porém os negros no Brasil me alertaram sobre a necessidade de considerar esses comentários oficiais com certa cautela, declarando que a causa seria o preconceito de cor. Um negro de destaque que serviu nas forças armadas me disse que, em 1937, revelou-se entre as autoridades uma preocupação com o aumento de militares judeus e negros. $\mathrm{O}$ meu informante, que manifestou a sua amargura com o tema, admitiu que há o esforço de corrigir esse problema, mas ainda fez a questão: "Por que um negro não pode se matricular numa academia do Exército, da Marinha ou da Força Aérea?”. Ele posteriormente afirmou que os negros não entram para o corpo diplomático do país.

Aquele oficial das forças armadas, mencionado acima, afirmou que há negros nas três academias, mas admitiu que havia discriminação na Marinha e na Força Aérea. O meu informante negro declarou que não há oficiais negros na Marinha e na Força Aérea, enquanto havia vários coronéis no Exército. Um deles recentemente se aposentou porque não conseguiu a sua promoção para general. Um negro general morreu recentemente. ${ }^{15}$

No relato sobre o Brasil, é possível perceber um conflito entre as narrativas de autoridades oficiais e de cidadãos negros. No segundo artigo sobre o país, no entanto, prevaleceu a perspectiva de militantes negros que atuavam na cidade do Rio de Janeiro. George Schuyler citou a importância de organizaçóes negras como a Uniáo dos Homens de Cor e o Teatro Experimental do Negro. ${ }^{16}$ No título do texto, o jornalista fez referência a uma "linha de

${ }^{15}$ SCHUYLER, George. Brazil's army polices shame United States. Pittsburgh Courier. 21 ago. 1948, p. 1. Tradução do autor. No original: "This officer declared that about 10 per cent of the Brazilian Army officer are Negro, while 60 per cent are mulatto and lighter, the remainder being white. He further stated that era three Negro generals and twenty Negro colonels. Since a quarter of the Brazilian population is black, he attributed the paucity of Negro officers to the difficulty of entrance and subsequent examinations in the military, naval and air corps academies. This is clearly the official view [...] But Negroes in Brazil who keep up on these matters not only warned me to accept the official statements on this matter with considerable reserve but flatly declared that the scarcity of Negro officers is due to color prejudice. One outstanding Negro who served several years in the Brazilian Army charged that in 1937 a secret order sent out advising against any increase in the number of Jews and Negroes in the Army. While this informant, who was quite bitter on the subject, admitted that presently the brass hats are attempting to rectify this policy, he asked: 'Why is it that a Negro cannot matriculate in the military, naval or air corps academics?' He further charged that a Negro cannot enter the diplomatic corps today. The aforementioned General Staff officer held that there was discrimination against them in the Navy or and Air Corps. The Negro informant flatly declared that there were no Negro officers in either the Navy or the Air Corps, and that while there were several Negro colonels in the Army, one ranking black colonel recently retired because he could not get his promotion to general. One Negro general is reported to have died recently".

${ }^{16}$ SCHUYLER, George. Brazilian colors bias growing more rampant. Pittsburgh Courier, 4 set. 1948, p. 1. 
cor desenfreada" para retratar as dificuldades encaradas pela população negra na sociedade brasileira. Logo no início, citou a experiência de uma mulher negra dos Estados Unidos que morava há anos na cidade de Salvador. Schuyler reproduziu o comentário da estrangeira de que "aqui a minha consciência de cor é muito maior". ${ }^{17}$ Ela destacou o destempero dos brasileiros com os negros e o fato de que uma mulher negra deveria se casar com um português para ascender socialmente.

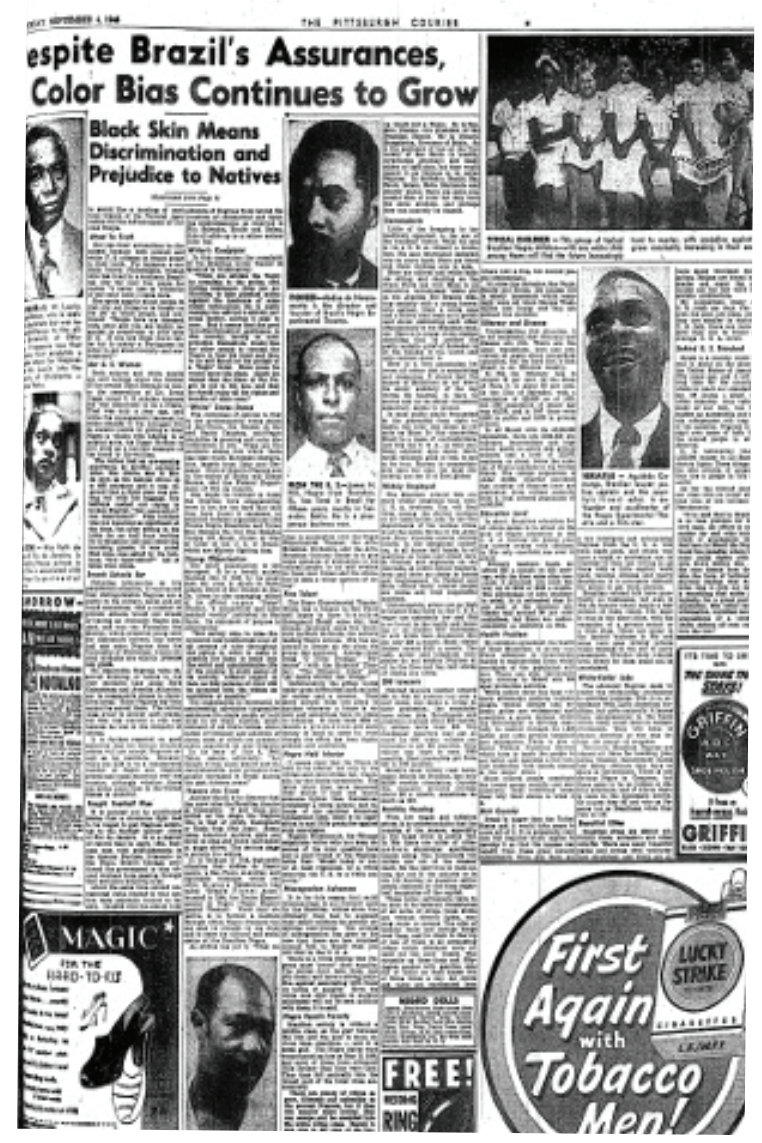

Figura 2: Página com o relato de George Schuyler sobre o Brasil.

O jornalista também tratou das dificuldades de os negros adentrarem espaços importantes, fazendo uma relação que ia desde hotéis até clubes de futebol. No quadro pintado por George Schuyler, a discriminação racial não era uma exceção, mas uma regra nas dinâmicas sociais. O problema ainda se acentuava no que o jornalista cunhou como "estados brancos", onde as políticas de imigração criaram uma maioria de origem europeia hostil a uma minoria de negros. 
Negros amargurados comentam que uma tremenda luta foi feita para a admissão de jogadores de futebol negros nos clubes do Rio de Janeiro. É importante registrar também que, em abril de 1944, um homem de negócios com estabelecimentos no "famoso Triangulo Paulista” em São Paulo (uma espécie de Chicago brasileira) pediu para que o governo proibisse os trabalhadores negros de transitarem pela área comercial. No mesmo período, clubes sociais negros localizados na mesma região foram "convidados a se retirar". Esse quadro, combinado à falta de negros nos comércios, agências bancárias, como observado no Rio, em Salvador, Recife e Belém, é possível afirmar que há um sério problema de cor. ${ }^{18}$

George Schuyler registrou também as relaçôes cotidianas entre brasileiros de diferentes tons de pele. Em seu esforço para compreender as relaçóes raciais no Brasil, oscilou entre a observação de que as tensóes raciais não estavam presentes e os comentários de militantes que apontavam para as nuances do "preconceito de cor" no Brasil. O jornalista, assim, destacou a cooperação entre negros, mulatos e brancos em diversos espaços de trabalho, mas simultaneamente enfatizou o status inferior dos negros na sociedade brasileira, afirmando que havia muitos brancos pobres e analfabetos que tinham uma facilidade maior para ascender socialmente devido à importância da "brancura" entre os brasileiros. A citação da figura de Abdias do Nascimento, nesse momento uma das lideranças do Teatro Experimental do Negro, indica a importância dos interlocutores negros no retrato da sociedade brasileira. $\mathrm{O}$ ativista despontava como uma liderança importante no cenário brasileiro, promovendo entre importantes intelectuais o debate sobre o "preconceito de cor" no país (MACEDO, 2005). George Schuyler foi entrevistado por Abdias do Nascimento e teve a sua imagem estampada na primeira ediçáo do jornal $O$ Quilombo, que teria a funçáo de divulgar as atividades do Teatro Experimental do Negro. A importância dada ao militante brasileiro no relato de Schuyler pode ser verificada no último trecho do artigo:

Dizem que no Brasil não há nenhum problema de raça para os negros. Há um enorme esforço para difundir a ideia de que aqui os negros encontraram um paraíso no qual podem desfrutar direitos iguais com outros homens. Não acreditem nisso... se o drama da raça no Brasil não se revela de forma belicosa ou através de enfrentamento físico, não significa que o problema não exista. $\mathrm{O}$ preconceito se manifesta psicologicamente para grande parte da população.

${ }^{18}$ Idem. Tradução do autor. No original: "It is pointed out by embittered blacks that a strenuous fight had to be waged to get Negroes admitted to the football (soccer) clubs of the Rio de Janeiro. It is matter of record that in April, 1944, business men establishments in the famous Paulista Triangulo in Sao Paulo, Brazil's Chicago, petitioned the government to stop colored workers from passing through that executive shopping area. About the same time colored recreational clubs located in that section were pointdely invited to the part. Coupled with the almost total absence of Negroes from behind he counters of commercial and banking establishments, as observed in Rio, Salvador, Recife, Belem, this all adds up to a rather serious color bar". 
A discriminação velada convive com a mistificação da constituição que afirma que todos os homens são iguais perante a lei. ${ }^{19}$

Apesar da influência de Abdias do Nascimento no retrato do Brasil feito por George Schuyler para os leitores do Pittsburgh Courier, é possível perceber nos relatos do jornalista uma preocupação anterior com o preconceito de cor no Brasil e em outros países da América Latina. Schuyler enfatizou a "complexidade" das relaçóes sociais em países nos quais a hierarquia racial não era estruturada por critérios rígidos de negritude e pela segregação racial. Um denominador comum nos relatos é a preocupação dos latino-americanos com a "brancura" e como ela orientava as estruturas sociais que viabilizavam a ascensão social daqueles considerados brancos e determinavam a marginalidade daqueles que apresentavam os traços físicos de ascendência africana. George Schuyler, diferentemente de Robert Abbott, que atribuiu os poucos casos de preconceito de cor à influência dos norte-americanos, identificou um conjunto de práticas discriminatórias que era próprio da história da América Hispânica e Portuguesa, chamando sempre a atenção dos leitores para o fato de que o problema do "preconceito de cor" já existir antes que os ianques passassem a influenciar politicamente em outros países das Américas.

\section{Conclusão}

Os relatos de George Schuyler sobre as experiências negras na América Latina para os leitores do Pittsburgh Courier desarticularam as representaçóes sobre paraísos raciais difundidas frequentemente pela própria imprensa afro-americana. Desde a década de 1850, alguns políticos e ativistas abolicionistas, que discutiam a violência do sistema escravista dos Estados Unidos, observavam a sociedade brasileira e as dinâmicas sociais da escravidão brasileira. Ao longo desse processo de comparação entre os sistemas escravistas, o Brasil emergiu como um espaço de fraternidade racial, em contraposição à formação de uma nova hierarquia racial no pós-abolição nos Estados Unidos. Assim, as imagens de um paraíso racial brasileiro foram acionadas por lideranças negras que lutavam contra a segregação racial e apontavam para alternativas civilizatórias na América Latina. Frederick Douglass e Robert Abbott foram figuras proeminentes do ativismo negro dos Estados Unidos que ajudaram a difundir essas representaçóes que se consolidaram ao longo da década de 1920.

${ }^{19}$ Idem. Tradução do autor. No original: "It is said that in Brazil there is no race problem for colored man. An effort is made to scatter far and wide before the winds of propaganda the idea that here in Brazil the Negro has found his paradise where them may enjoy equal rights with other men. Don't believe this... If the race drama here does not take the form of bellicosity and physical clashes, that does not mean that it does not exists. It is something that exists psychologically for a great part of the population, this velled racial discrimination, mystified among the propositions of a constitution which defines all men equal before the law". 
Quando George Schuyler rumou à América Latina para retratar o processo de integração dos negros, também acreditava na singularidade das relaçóes raciais dos latino-americanos, principalmente dos brasileiros. Entretanto o intelectual afro-americano interpretou de maneira diferente a sociedade brasileira, chegando à conclusão de que as fraternidades raciais da América Latina não eram uma realidade. Não há dúvidas de que Abdias do Nascimento tenha influenciado Schuyler, embora seja possível perceber alguns aspectos observados pelo intelectual afro-americano associados ao debate sobre a questão racial nos Estados Unidos. George Schuyler, em seu relato sobre o Brasil, reproduziu a perspectiva de Abdias do Nascimento, que criticara a afirmação de que não existia preconceito de cor no Brasil, mas não deixou de questionar as relaçóes raciais em países como a Venezuela, indicando que, apesar do processo de miscigenação, a branquitude era um elemento fundamental nas dinâmicas sociais do país, determinando uma política de imigração voltada para trabalhadores europeus. Portanto, as práticas discriminatórias que inviabilizavam a ascensão social das populações negras na América Latina, de acordo com Schuyler, não eram consequência de influências exógenas, mas parte de uma hierarquia que se estruturou historicamente no Brasil e nos demais países do continente.

\section{Fontes primárias}

SCHUYLER, George. View and review. Pittsburgh Courier, 18 jul. 1931.

SCHUYLER, George. Views and reviews. Pittsburgh Courier, 31 jan. 1942, p. 3.

SCHUYLER, George. Racial integration works in Cuba's army. Pittsburgh Courier, 17 jul. 1948 , p. 1.

SCHUYLER, George. America's canal zone policy is a disgrace. Pittsburgh Courier, 31 jul. 1948 , p. 1.

SCHUYLER, George. Segregation does not exist in Venezuelan Armed Forces. Pittsburgh Courier, 24 jul. 1948, p. 1.

SCHUYLER, George. Negroes gradually vanishing in Peru. Pittsburgh Courier, 7 ago. 1948, p. 1.

SCHUYLER, George. Colombia's army gives...to US brass hats. Pittsburgh Courier. 14 ago. 1948 , p. 1.

SCHUYLER, George. Negroes negligible factor in Uruguay. Pittsburgh Courier. 28 ago. 1948 , p. 1.

SCHUYLER, George. Brazil's army polices shame United States. Pittsburgh Courier. 21 ago. 1948 , p. 1. 
SCHUYLER, George. Brazilian colors bias growing more rampant. Pittsburgh Courier, 4 set. 1948 , p. 1.

SCHUYLER, George S. [correspondência]. Destinatário: William G. Nunn, 1962. Schuyler Papers - Syracuse University.

\section{Referências}

ANDREWS, George. América Afro-Latina, 1800-2000. São Carlos: EdUFSCAR, 2007.

BEITO, Linda Royster. Selling Laissez-faire antiracism to the Black Masses: Rose Wilder Lane and the Pittsburgh Courier. The Independent Review, fall 2010, 15, 2.

BORM, Jam. Defining travel: on the Travel Book, Travel Writing and Terminology. In: HOOPER, Glenn; YOUNGS, Tim (org.). Perspectives on Travel Writing. London: Ashgate Publishing, 2004.

BRACEY, Christhoper A. Saviours or Sellouts: the promise and peril of Black conservatism, from Booker T. Washington to Condoleeza Rice. Boston: Beacon Press, 2008.

BREWER Jr., John H. African Americans in Pittsburgh. Chicago: Arcadia Publishing, 2006. BUNI, Andrew. Robert L. Van of the Pittsburgh Courier: politics and Black journalism. Pittsburgh: University of Pittsburgh Press, 1974.

CAPELATO, Maria Helena; PRADO, Maria Lígia. O bravo matutino: imprensa e ideologia no jornal O Estado de São Paulo. São Paulo: Alfa Omega, 1980.

GREENBERG, Cheryl Lynn. To Ask an Equal Chance: African-Americans in Great Depression. Plymouth: Rowman \& Littlefield Publishers, 2009.

EISENSTADT, Peter (org.). Black Conservatism: essays in intellectual and political history. New York: Routledge, 2012.

FRANCISCO, Flávio Thales Ribeiro. O novo negro na diáspora: modernidade afro-americana e as representações sobre o Brasil e a França no jornal Chicago Defender (1916-1940). São Paulo: Intermeios/FAPESP, 2016.

GOTTLIEB, Peter. Making Their Own Way: southern blacks' migration to Pittsburgh, 1916-30. Urbana: University of Illinois Press, 1987.

GREGORY, James N. The Southern Diaspora: how great migrations of black and white southerners transformed America. Chapel Hill: University of North Carolina Press, 2005. GROSSMAN, James R. Land of Hope: Chicago, Black Southerners, and the Great Migration. University of Chicago Press, 1989. 
HELLWIG, David J. (org.). African-American Reflections on Brazil's Racial Paradise. Philadelphia: Temple University Press, 1992.

HUTTON, Frankie. The Early Black Press in America, 1827-1860. Westport: Greenwood Publishing Group, 1992.

JACOBSON, Matthew Frye. Whiteness of a Different Color: European immigrants and the alchemy of race. Cambridge: Harvard University Press, 1999.

KATZNELSON, Ira. When Affirmative Action Was White: an untold history of racial inequality in twenty-century America. New York: W. W. Norton \& Company, 2006.

KIRK, Russel. The Conservative Mind: from Burke to Eliot. Washington DC: Regnery Publishing, 2001.

LEAK, Jeffrey B. (org.). Racle]ing to the Right: selected essays of George S. Schuyler. Knoxville: The University of Tennessee Press, 2001.

LEJEUNE, Philippe. O pacto autobiográfico: de Rousseau à internet. Belo Horizonte: Editora UFMG, 2008.

LENTHZ-SMITH, Adriane Danette. Freedom Struggles: African Americans and World War I. Cambridge: Harvard University Press, 2009.

LIMONCIC, Flavio. Os inventores do New Deal: Estado e sindicatos no combate à Grande Depressão. Rio de Janeiro: Civilização Brasileira, 2009.

MACEDO, Márcio de José. Abdias do Nascimento: a trajetória de um negro revoltado (1914-1968). Dissertaçáo (Mestrado em Sociologia), Departamento de Sociologia da FFLCH/USP, 2005.

MARTINS, Ana Luiza; LUCA, Tânia Regina de. História da imprensa no Brasil. São Paulo: Contexto, 2008.

MILLER, Kelly. Radicals \& Conservatives and Others Essays on the Negro in America. New York: Schoken Books, 1968.

NASH, George. The Conservative Intellectual Movement in America Since 1945. Wilmington, Delaware: Intercollegiate Studies Institute, 2006.

O'REILLY, Kenneth. Nixon's Piano: presidents and racial politics from Washington to Clinton. New York: Free Press, 1995.

POGGI, Tatiana. Os opositores conservadores do New Deal. Revista Eletrônica da ANPHLAC, v. 7, p. 27-56, 2008.

PRATT, Mary Louise. Os olhos do império: relatos de viagem e transculturação. São Paulo: EDUSC, 1999.

PRIDE, Armistead S. \& WILSON II, Clint C. A History of the Black Press. Washington, D.C.: Howard University Press, 1997. 
RAWNS Jr., James. The Double V: how wars, protest, and Harry Truman desegregated America's military. New York: Bloomsbury Press, 2013.

SHAW-THORNBURG, Angela. Reading and Writing African American Travel Narrative. Tese (Doutorado em Literatura Americana), Rutgers, State University of New Jersey, 2006. SCHUYLER, George S. Black no More. New York: Maucalay Co. 1931a.

SCHUYLER, George S. Slaves of Today. A Story of Liberia. New York: Brewer, Warren and Putnam, $1931 b$.

SCHUYLER, George S. Black and Conservative: the autobiography of George Schuyler. New Rochelle: Arlington House Publishers, 1966.

SITIKOFF, Harvard. A New Deal for Blacks: the emergence of civil rights as a national issue: the Depression Decade. Oxford: Oxford University Press, 2009.

SMITH, Virginia Whatley. African American travel literature. In: BENDIXEN, Alfred; HAMERA, Judith (ed.). The Cambridge companion to American travel literature. Cambridge: Cambridge University Press, 2009.

SIRINELLI, Jean-François. Os intelectuais. In: RÉMOND, René. Por uma história politica. Rio de Janeiro: Ed. UFRJ/Ed. FGV, 1996.

SUGGS, Henry Lewis. P. B. Young, Newspaperman: Race, Politics and Journalism in the New South, 1910-1962. Charlottesville, Va.: University Press of Virginia, 1988.

WALKER, Lee H. Rediscovering Black Conservatism. Chicago: The Heartland Institute, 2009.

WASHBURN, Patrick. The Pittsburgh Courier's Double V campaign in 1942. Paper presented at $64^{\text {th }}$ Annual Meeting of the Association for Education in Journalism. East Lansing, Michigan, 8-11 August, 1981.

WASHINGTON, Booker T. Up from slavery. Nova York: Dover Publications, 1995.

WATSON, Shelly L. The Pittsburg Courier: advocate for integration of the U.S. Armed Forces (1934-1940). Dissertação (Mestrado em Comunicação), San Jose State University, 2013.

WEISS, Nancy J. Farewell to the Party of Lincoln: black politics in the age of FDR. Princeton: Princeton University Press, 1983.

WILLIAMS, Harry M. When Black is Right. the life and writings of George S. Schuyler. Tese (Doutorado em História), Brown University, 1988.

WILLIAMS, Oscar R. George S. Schuyler: portrait of a black conservative. Knoxville: University of Tennessee Press, 2007.

WRIGHT, Leah Michele. The Loneliness of Black Conservatives: black republicans and the Grand Old Party, 1964-1980. Tese (Doutorado em História), Princeton University, 2009. 